\title{
Bacteriófagos en el control biológico de Pseudomonas syringae pv. phaseolicola agente causal del tizón de halo del frijol
}

\section{Bacteriophages in the biological control of Pseudomonas syringae pv. phaseolicola, causal agent of halo blight in bean}

\author{
Evangelina Esmeralda Quiñones-Aguilar ${ }^{1}$, Alfredo Reyes-Tena ${ }^{1}$, Luis Guillermo Hernández-Montiel ${ }^{2}$, Gabriel \\ Rincón-Enríquez ${ }^{1 *}$ \\ ${ }^{1}$ Biotecnología Vegetal, Centro de Investigación y Asistencia en Tecnología y Diseño del Estado de Jalisco A. C., Camino \\ Arenero Núm. 1227, Col. El Bajío del Arenal, CP. 45019. Zapopan, Jalisco México. \\ ${ }^{2}$ Centro de Investigaciones Biológicas del Noroeste, Calle Instituto Politécnico Nacional No. 195, Col. Playa Palo de Santa Rita \\ Sur, CP. 23096, La Paz, Baja California Sur, México. \\ *Autor de correspondencia: grincon@ciatej.mx
}

Artículo científico recibido: 12 de julio de 2016 aceptado: 05 de diciembre de 2017

RESUMEN. Pseudomonas syringae pv. phaseolicola (Psph) es el agente causal del tizón de halo del cultivo de frijol. El manejo de esta enfermedad está basado en antibióticos agrícolas o compuestos a base de cobre. Una alternativa es el control biológico con virus bacterianos (bacteriófagos). Por lo anterior, el objetivo del trabajo fue evaluar el efecto de bacteriófagos nativos del estado de Zacatecas en el control de cepas virulentas de Psph. Se realizaron tres experimentos: 1) se evaluó la patogenicidad y virulencia de seis cepas de Psph y la cepa de referencia $1448 \mathrm{~A}$ en ejotes y plantas de frijol variedad Negro Bolita; 2) se evaluó la virulencia de las tres cepas más agresivas en la variedad Flor de Mayo que presenta mayor tolerancia al tizón de halo; y 3) se evaluaron siete bacteriófagos para determinar el control biológico del tizón en la cepa nativa Psph1 y la cepa 1448A en ejotes de frijol variedad Flor de Mayo. Se cuantificó el área del tizón de halo en $\mathrm{mm}^{2}$, se encontró que las seis cepas Psph nativas fueron patogénicas en ejotes y plantas de frijol; la virulencia de mayor a menor grado fue: 1448A (7.5 mm²); Psph67 (5.3 mm $\mathrm{mm}^{2}$ y Psph1 (3.8 mm²). Solo un bacteriófago (F2) redujo de forma significativa $(\mathrm{p} \leq 0.05)$ un $60 \%$ el área provocada por la cepa $1448 \mathrm{~A}$ en ejotes. Los resultados sugieren que la tecnología de los bacteriófagos podría ser una estrategia para el control biológico del tizón de halo del cultivo de frijol en la agricultura mexicana.

Palabras clave: Biocontrol, Phaseolus vulgaris, bacteriófagos, tizón del halo, lisis bacteriana

ABSTRACT. Pseudomonas syringae pv. phaseolicola (Psph) is the causal agent of halo blight in bean. Management of this disease is based on agricultural antibiotics or copper-based compounds. An alternative is biological control with bacterial viruses (bacteriophages). Therefore, the aim of this study was to evaluate the effect of bacteriophages native to the state of Zacatecas in the control of virulent strains of Psph. Three experiments were carried out: 1) the pathogenicity and virulence of six strains of Psph and the reference strain 1448A were evaluated in green beans and Negro Bolita variety bean plants; 2) the virulence of the three most aggressive strains was evaluated in the Flor de Mayo variety, which shows greater tolerance to halo blight; and 3) seven bacteriophages were evaluated to determine the biological control of the blight in the native strain Psph1 and strain 1448A in Flor de Mayo variety green beans. The halo blight area was quantified in $\mathrm{mm}^{2}$; it was found that the six native Psph strains were pathogenic in green beans and bean plants. Virulence from highest to lowest degree was: 1448A $\left(7.5 \mathrm{~mm}^{2}\right)$; Psph67 (5.3 mm²) and Psph1 $\left(3.8 \mathrm{~mm}^{2}\right)$. Only one bacteriophage (F2) significantly reduced $(\mathrm{p} \leq 0.05)$, by $60 \%$, the area caused by strain $1448 \mathrm{~A}$ in green beans. The results suggest that bacteriophage technology could be a strategy for the biological control of halo blight in bean in Mexican agriculture.

Key words: Biocontrol, Phaseolus vulgaris, bacteriophages, halo blight, bacterial lysis 


\section{INTRODUCCIÓN}

El tizón de halo del frijol provocado por Pseudomonas syringae pv. phaseolicola (Psph), es una enfermedad importante del frijol, llegando a provocar pérdidas de hasta un $43 \%$ de la producción (Schwartz 1989); al respecto Lépiz et al. (2015) indican que en Jalisco esta enfermedad causa daños severos, con pérdidas mayores al 50\%. En México el frijol es un cultivo de gran importancia económica debido a que es la segunda leguminosa en importancia comercial, al ser uno de los alimentos más consumidos (Lara-Flores 2015). Su cultivo se desarrolla principalmente en los estados del centronorte de México, donde el tizón de halo es uno de los principales problemas fitosanitarios (PrudencioSains et al. 2008). Para el control efectivo de esta enfermedad dentro del marco de la agricultura sustentable se encuentra el control biológico, que consiste en la aplicación de enemigos vivos para combatir el establecimiento y desarrollo de los agentes fitopatógenos (Reyes-Tena et al. 2015). Se conocen virus capaces de romper o lisar células bacterianas fitopatógenas llamados bacteriófagos, los cuales fueron descubiertos por D'Herelle, al encontrar placas de lisis sobre cultivos bacterianos (D’Herelle 1917). El desarrollo de la aplicación de los bacteriófagos dentro del control biológico en la agricultura se detuvo por el uso de antibióticos, los cuales fueron efectivos y de fácil producción. Sin embargo, en la actualidad el desarrollo de resistencia a antibióticos por parte de las bacterias fitopatógenas, conlleva a la búsqueda de nuevas alternativas de manejo y control, donde el empleo de bacteriófagos tiene potencial de aplicación (Frampton et al. 2012).

Estudios recientes muestran que los bacteriófagos son efectivos en la disminución del daño causado por bacterias fitopatógenas, al respecto Adachi et al. (2012) encontraron que el bacteriófago BGPP-Ar controló a las bacterias Burkholderia glumae y Burkholderia plantarii agentes causales de la pudrición de plantas de arroz, al inocularse en concentraciones de $1 \times 10^{5}-1 \times 10^{8}$, disminuyendo la podredumbre de plántulas. Pero los bacteriófagos son sensibles a las condiciones ambientales, como la radiación solar, la temperatura y la desecación (Iriarte et al. 2007), por ello se han desarrollado formulaciones de protección para aumentar la actividad residual e incrementar su eficacia y fiabilidad (Balogh et al. 2010). En este sentido, Balogh et al. (2008) evaluaron diferentes bacteriófagos co-inoculados con leche descremada y bactericidas a base de cobre contra Xanthomonas axonopodis pv. citri y citrumelo agentes causales del cancro de los cítricos bajo invernadero, reportando una disminución promedio del $59 \%$ de la enfermedad. Mientras que Iriarte et al. (2012) al evaluar bacteriófagos inoculados en la rizósfera de plantas de tomate encontraron una prevalencia y translocación de los bacteriófagos en diferentes tejidos de la planta, además del control de la marchitez bacteriana mediante la inoculación de mezclas de bacteriófagos tres días antes de la inoculación de las bacterias fitopatógenas Ralstonia solanacearum, Xanthomonas perforans y Xanthomonas euvesicatoria. Con base en lo anterior, el objetivo de este trabajo fue evaluar el efecto de bacteriófagos nativos de Zacatecas en el control de cepas virulentas de Psph en ejotes frescos de frijol.

\section{MATERIALES Y MÉTODOS}

\section{Origen de las cepas bacterianas utilizadas}

De una colección de 85 aislados de Pseudomonas sp. del banco de bacterias del área de fitopatología de la Unidad de Biotecnología Vegetal del CIATEJ, se identificaron seis cepas como $P$. syringae pv. phaseolicola mediante análisis de amplificación de la región ITS (Intergenic Transcribed Spacer); con la metodología propuesta por Jensen et al. (1993), lo que produce información de la variación en longitud y secuencia del ADN ribosomal 16S-23S típica de la especie bacteriana bajo estudio; información que fue comparada con la cepa tipo 1448A (Joardar et al. 2005). Las cepas estudiadas fueron: Psph1, Psph58, Psph67, Psph69, Psph74 y Psph82, que se aislaron del follaje de plantas de frijol con tizón de halo de las variedades Flor de Mayo, Bayo y Negro Bolita de parcelas de Calera, 


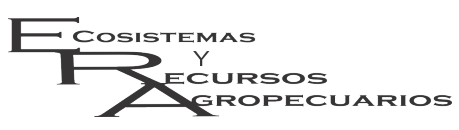

General Enrique Estrada y Fresnillo, municipios del estado de Zacatecas, en el ciclo agrícola de temporal 2014. El tejido vegetal enfermo se mantuvo a $4{ }^{\circ} \mathrm{C}$ antes de procesarse para el aislamiento con el método de dilución decimal en medio de cultivo estéril selectivo King B (2\% de peptona de carne, $8.5 \mathrm{mM}$ de $\mathrm{K}_{2} \mathrm{HPO}^{4}, 6.06 \mathrm{mM}$ de $\mathrm{Mg} 2 \mathrm{SO} 4,1.2 \%$ de glicerol, $\mathrm{pH}$ de 7.2 , y $1.6 \%$ de agar).

\section{Evaluación de la patogenicidad de Psph en ejote de frijol}

Se realizó un experimento para determinar la capacidad de las seis cepas aisladas de Psph para producir tizón de halo en ejotes de plantas de frijol variedad Flor de Mayo. Se evaluaron los volúmenes de $5,10,15$ y $20 \mu \mathrm{L}$ de una suspensión bacteriana de $2 \times 10^{8}$ UFC $\mathrm{mL}^{-1}$. Como control negativo se empleó inóculo de la cepa $\mathrm{DH} 5 \alpha$ de Escherichia coli (no fitopatógena) y como control positivo la cepa tipo 1448A de Psph con alta capacidad de virulencia (Joardar et al. 2005). La unidad experimental (UE) fue un ejote de una longitud de entre 8 y $10 \mathrm{~cm}$ con los cuatro volúmenes de inóculo por cepa de Psph más la cepa de $E$. coli. Los ejotes se produjeron bajo condiciones de invernadero sin aplicación de bactericidas o fungicidas, cosechados entre 45 y 50 $\mathrm{d}$ despues de la siembra. Para la inoculación de las bacterias se realizó un orificio con una aguja de disección estéril, posteriormente en cada orificio se depositaron las diferentes concentraciones de suspensión bacteriana del menor al mayor volumen y al final la cepa DH5 $\alpha$ (Figura 1). Las UE se colocaron sobre papel absorbente húmedo dentro de una caja de plástico cerrada a temperatura constante de 26 ${ }^{\circ} \mathrm{C}$ para favorecer la infección. Después de $96 \mathrm{~h}$ se registraron las lesiones causadas por las cepas de Psph, y si causaban clorosis, necrosis o tizón de halo.

\section{Determinación de la virulencia de las cepas Psph}

Para evaluar la severidad del tizón de halo de las cepas de Psph se usaron ejotes con dos días de cosecha de la variedad Negro Bolita y Flor de Mayo. En el primer ensayo se evaluaron 8 tratamientos: Psph1, Psph58, Psph67, Psph69,
Quiñones-Aguilar et al. Biocontrol de Pseudomonas syringae mediante bacteriófagos Ecosist. Recur. Agropec. 5(14):191-202,2018

Psph74, Psph82, 1448A y DH5 $\alpha$, en la variedad Negro Bolita. Luego se realizó un experimento con 4 tratamientos en la variedad Flor de Mayo, las dos cepas con mayor virulencia del primer experimento (Psph1 y Psph67) y como testigo las cepas $1448 \mathrm{~A}$ y BV007 de Bacillus pumilus, en ambos experimentos se empleó un diseño completamente al azar con 10 repeticiones por tratamiento. En cada ejote se inocularon $20 \mu \mathrm{L}$ de suspensión bacteriana a concentración de $2 \times 10^{8}$ UFC $\mathrm{mL}^{-1}$. Se determinó el área afectada del tejido vegetal mediante el registro del diámetro del tizón de halo. Los datos del área se analizaron mediante análisis de varianza ( $p \leq$ $0.05)$ y prueba de comparación múltiple de medias de Tukey $(\mathrm{p} \leq 0.05)$.

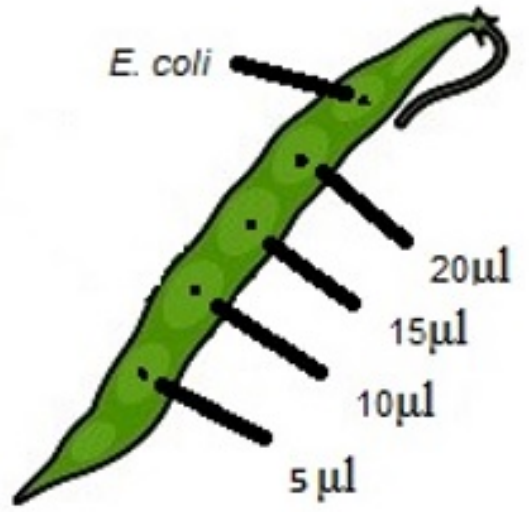

Figura 1. Esquema de la inoculación de distintos volúmenes de Pseudomonas syringae pv. phaseolicola y la cepa $\mathrm{DH} 5 \alpha$ de Escherichia coli para evaluar su patogenicidad en ejote de frijol.

\section{Evaluación de la patogenicidad de Psph en plantas de frijol}

Se realizó un experimento en el que se evaluaron las cepas Psph1, Psph58, Psph67, Psph69, Psph74, Psph82, 1448A y DH5 $\alpha$ en las variedades de frijol Negro Bolita, con crecimiento indeterminado tipo II; Flor de Mayo con crecimiento indeterminado tipo III; Pinto Saltillo con crecimiento indeterminado tipo III y Azufrado con crecimiento determinado tipo I, usando tres plántulas por variedad de frijol. Las semillas de frijol se depositaron dentro de tacos para su germinación por ocho días, posteriormente las plántulas 
se trasplantaron a macetas de unicel de $1 \mathrm{~L}$ de capacidad, con $800 \mathrm{~g}$ de sustrato estéril compuesto por $60 \%$ de arena, $30 \%$ de suelo, $8 \%$ de sunshine ${ }^{R}$ y $2 \%$ de vermicomposta. Las plántulas se inocularon con $25 \mu \mathrm{L}$ de cultivo bacteriano a concentración de $2 \times 10^{8}$ UFC $\mathrm{mL}^{-1}$. El inóculo se colocó en el foliolo apical de las primeras dos hojas compuestas (Figura 2), para lo cual se realizaron microheridas en el tejido foliar con carburo de silicio.

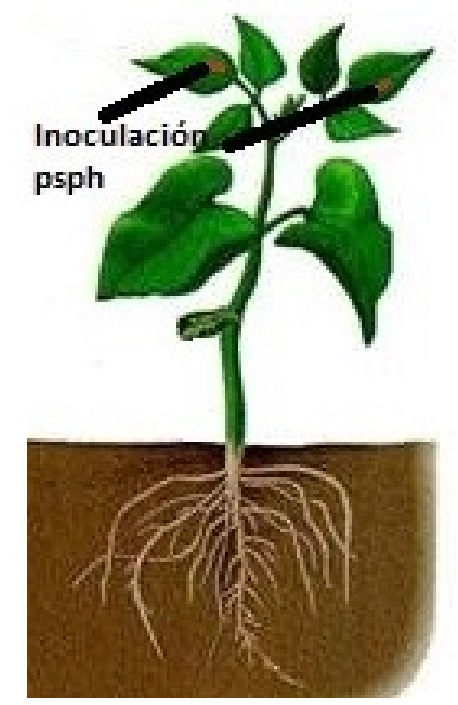

Figura 2. Esquema indicando los sitios de inoculación (flechas negras) de las cepas de Pseudomonas syringae pv. phaseolicola (psph) en el foliolo apical de las primeras dos hojas trifoliadas en plantas de frijol.

Biocontrol del tizón de halo provocado por Psph mediante bacteriófagos en ejotes de frijol

Se evaluaron los bacteriófagos: fago1 (F1), fago2 (F2), fago3 (F3), fago4 (F4) y fago5 (F5), aislados de la cepa 1448A y un bacteriófago aislado de la cepa Psph1 (F1.1). Se emplearon ejotes frescos de la variedad Flor de Mayo en un experimento con los siguientes tratamientos: sin fago (1448A), F1 (1448A+F1), F2 (1448A+F2), F3 (1448A+F3), F4 (1448A+F4), F5 (1448A+F5), F6 $(1448 \mathrm{~A}+\mathrm{F} 6)$; otros dos tratamientos se inocularon con la cepa Psph1, más los siguientes tratamientos: sin fago (Psph1) y F1.1 (Psph1+F1.1); en el último tratamiento se aplicó $\mathrm{H}_{2} \mathrm{O}$. Se inocularon
$20 \mu \mathrm{L}$ de suspensión bacteriana a concentración de $2 \times 10^{8}$ UFC $\mathrm{mL}^{-1}$. Quince minutos después de la inoculación bacteriana se colocaron $40 \mu \mathrm{L}$ de suspensión de bacteriófagos a concentración de $4 \times 10^{8}$ unidades formadoras de placa (UFP) $\mathrm{mL}^{-1}$. En cada ejote se colocaron cinco tratamientos (Figura 3), con seis repeticiones. Se determinó el área de daño del tizón de halo mediante la medición del diámetro del halo de maceración. Los datos se sometieron a análisis de varianza $(p \leq 0.05)$ y pruebas de comparación de medias de Tukey $(\mathrm{p} \leq 0.05)$.

\section{RESULTADOS}

\section{Evaluación de la patogenicidad de Psph en ejote}

Las cepas de Psph1, Psph54, Psph67, Psph69, Psph74 y Psph82 provocaron síntomas típicos del tizón de halo del frijol con halos cloróticos y necróticos (Figura 4A). Por lo que todas las cepas fueron patogénicas para ejotes de frijol de la variedad Flor de Mayo, presentando los mayores síntomas al inocular un volumen de $20 \mu \mathrm{L}$ del inoculo bacteriano (Figura 4B).

Determinación de la virulencia de Psph en ejote de frijol

Las diferentes cepas de Psph evaluadas en el ensayo fueron virulentas al mostrar distinto grado de sintomatología del tizón de halo en ejotes de la variedad Negro Bolita, que es un material susceptible a esta enfermedad; lo que produjo diferencias estadísticamente significativas $(p \leq 0.05)$ en el área de daño provocada por el tizón de halo (Figura 5A, B). El control positivo 1448A fue altamente virulento al mostrar la mayor área de daño en los halos acuosos, seguido de la cepa Psph1 que fue estadísticamente similar a las cepas Psph58, Psph67, Psph69 y Psph74. Las cepas que mostraron el menor nivel de virulencia fueron las cepas Psph82, Psph58, Psph67, Psph69 y Psph74. Mientras que el control negativo (DH5 $\alpha$ ) no mostró daños por enfermedad, mostrando sólo daños mecánicos ocasionados durante la inoculación. Presentando de mayor a menor grado de virulencia las cepas Psph1448A, Psph1 y 

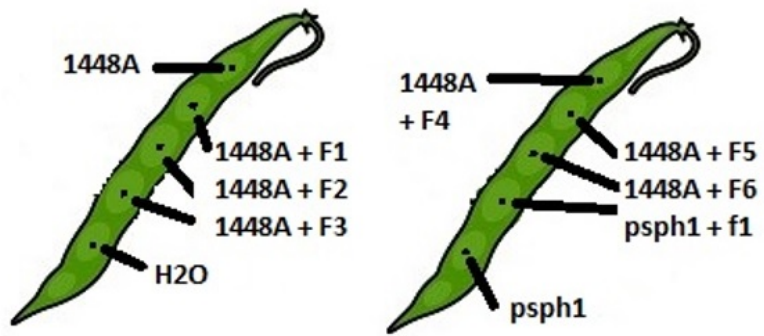

Figura 3. Esquema de la inoculación de los diez tratamientos del biocontrol del tizón de halo provocado por Pseudomonas syringae pv. phaseolicola (psph) a través de bacteriófagos ( $F)$ empleando ejotes de frijol.

(A)

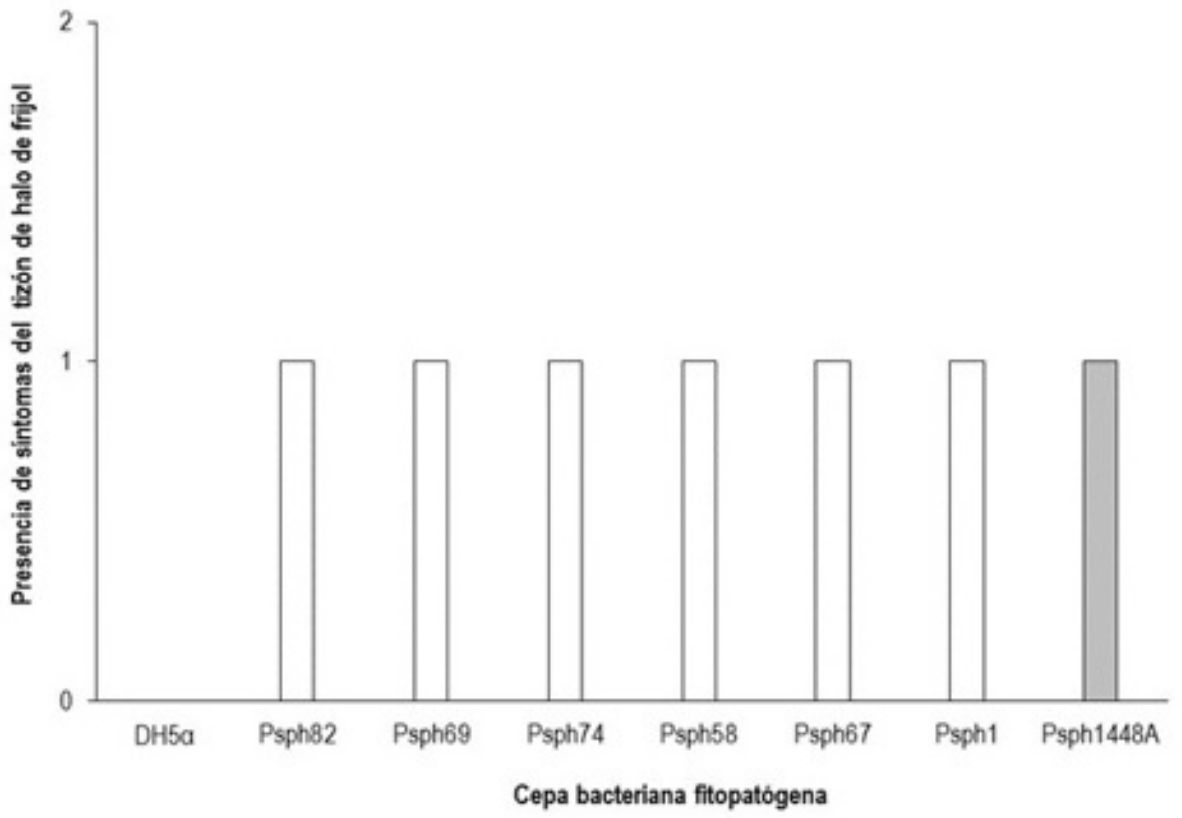

(B)

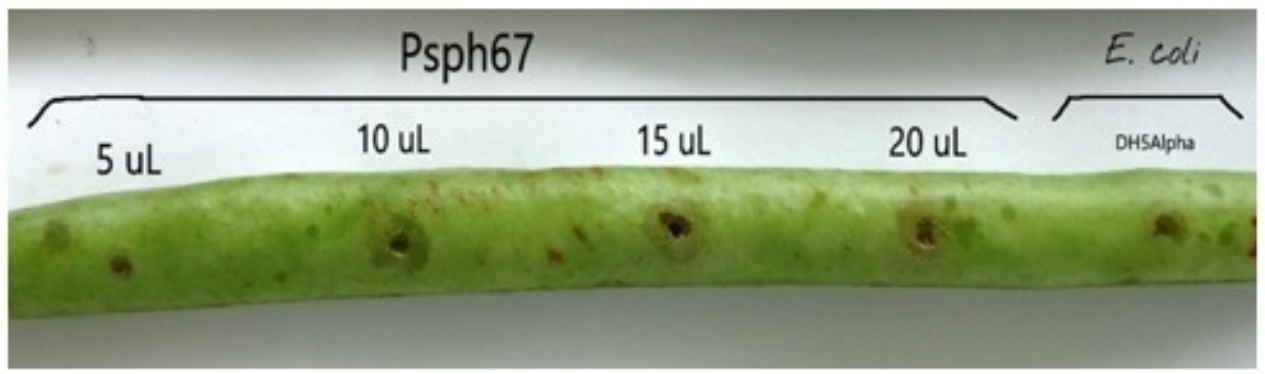

Figura 4. Patogenicidad de seis aislados de Pseudomonas syringae pv. phaseolicola (Psph) en ejotes de frijol variedad Flor de Mayo. (A) Observación de síntomas del tizón de halo en ejotes de frijol en aislados de Psph, de la cepa tipo 1448 A (barra gris) y de la cepa DH5 $\alpha$ de $E$. coli; valor $0=\sin$ síntomas; valor $1=$ con síntomas. (B) Daño mostrado por la cepa Psph67 en ejote de frijol al inocular 5, 10, 15 y $20 \mu \mathrm{L}$ de bacteria $\left(2 \times 10^{8}\right.$ UFC $\left.\mathrm{mL}^{-1}\right)$. 
Quiñones-Aguilar et al.

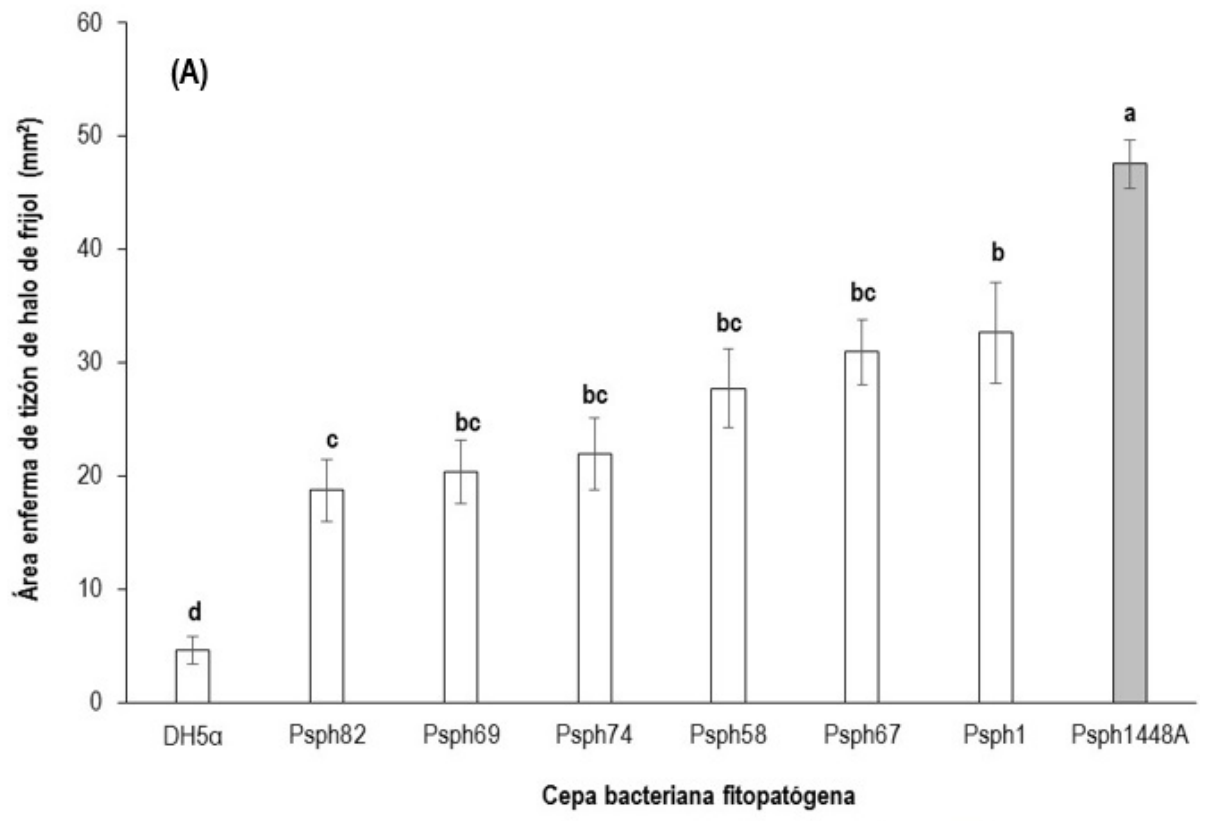

(B)

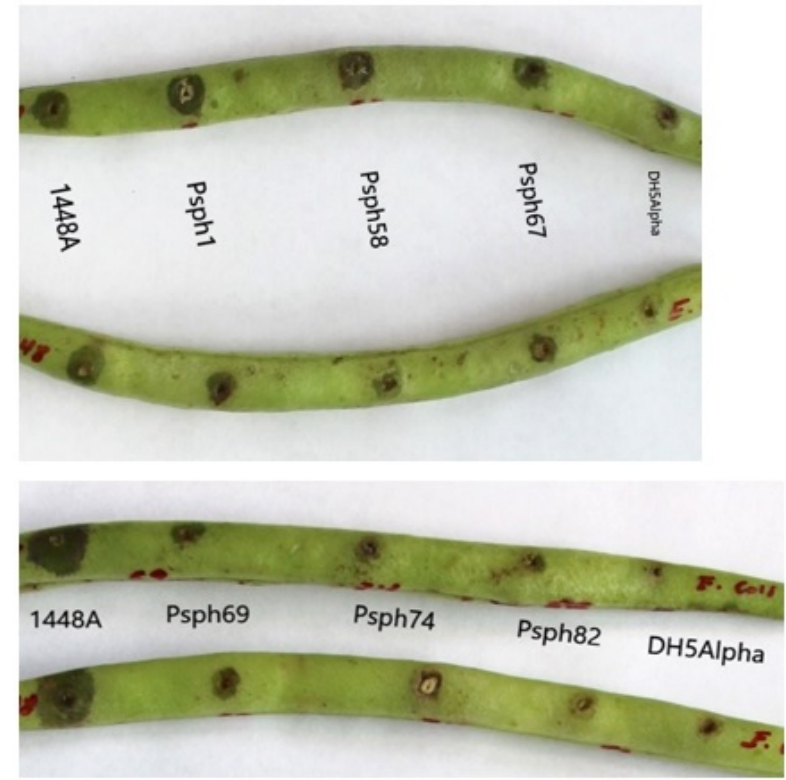

Figura 5. Virulencia de cepas de Pseudomonas syringae pv. phaseolicola (Psph) cuantificadas mediante el daño ocasionado en ejote de frijol variedad Negro Bolita. (A) Análisis estadístico del área enferma. Letras diferentes indican diferencias estadísticas de acuerdo a Tukey $(\mathrm{p} \leq 0.05)$. Las barras en cada rectángulo indican \pm el error estándar. DH $5 \alpha$ es una cepa de E. coli. La barra gris corresponde a la cepa Psph1448A. (B) Vista general de la virulencia provocadas por las distintas cepas bacterianas (Psph y E. coli). 


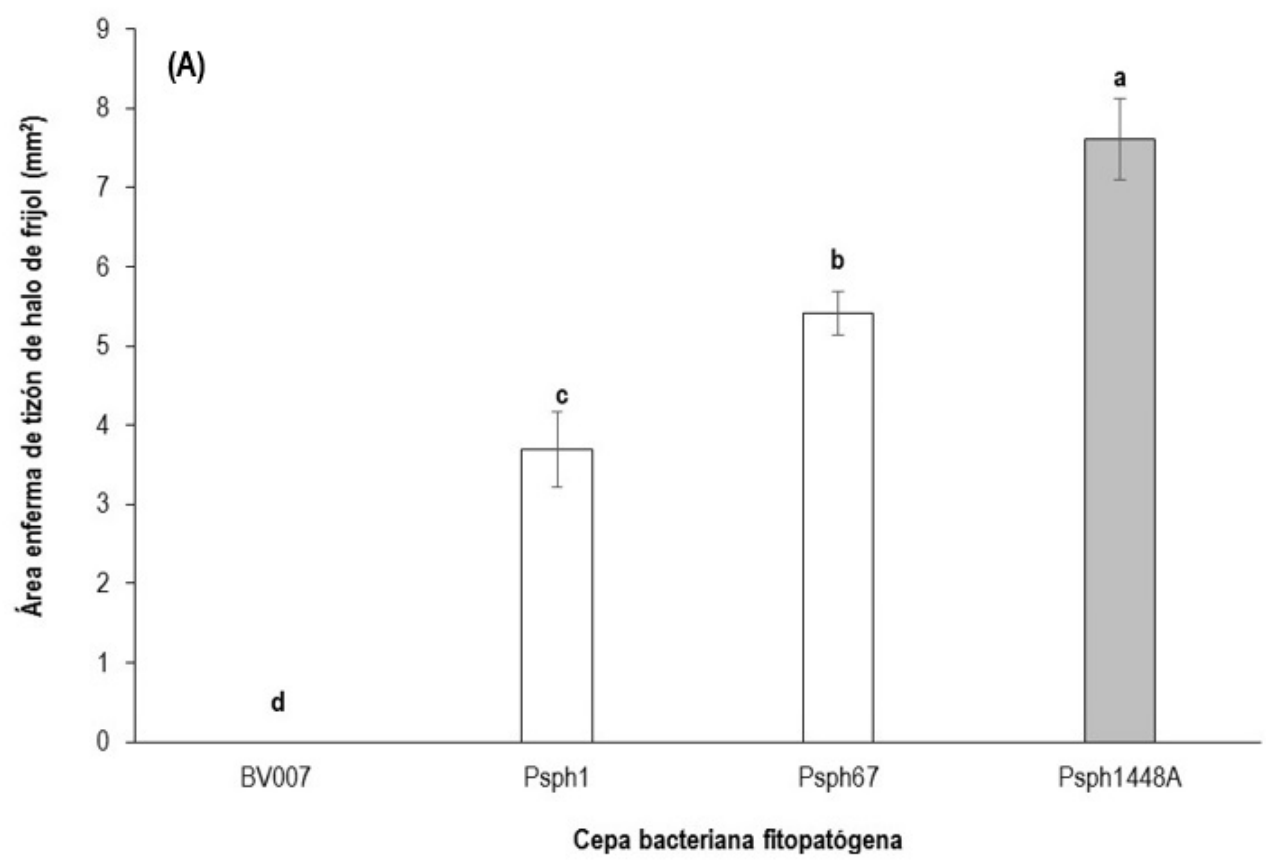

(B)

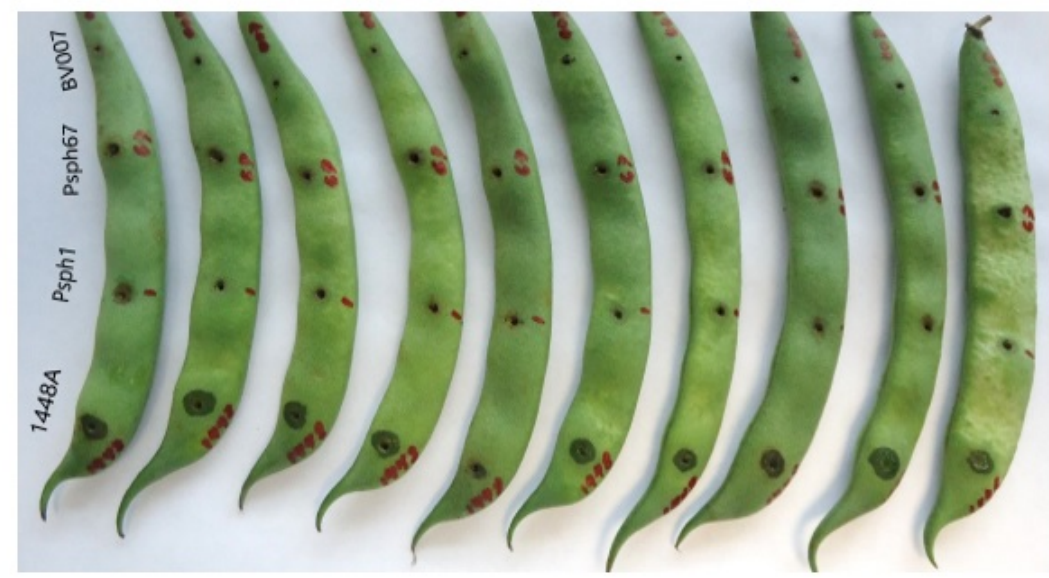

Figura 6. Virulencia de cepas de Pseudomonas syringae pv. phaseolicola (Psph) cuantificadas mediante el daño ocasionado en ejote de frijol variedad Flor de Mayo. (A) Análisis estadístico del área enferma. Letras diferentes indican diferencias estadísticas de acuerdo con Tukey $(\mathrm{p} \leq 0.05)$. Las barras en cada rectángulo indican \pm el error estándar. BV007 es una cepa de Bacillus pumilus. La barra en gris representa a la cepa control (1448A). (B) Vista general de la virulencia provocada por las distintas cepas bacterianas (Psph y BV007).

Psph67; por lo que se evaluaron en una variedad de frijol con mayor tolerancia a la enfermedad, para lo cual se empleó la variedad Flor de Mayo.

En la prueba de patogenicidad realizada sobre ejotes variedad Flor de Mayo, se encontraron diferencias estadísticas $(\mathrm{p} \leq 0.05)$ en el área de daño del tizón de halo en las tres cepas de Psph
(Figura 6A). La cepa Psph1448A mostró la mayor área de daño (Figura 6A, B). De las cepas nativas de Zacatecas (Psph67 y Psph1) las dos mostraron daño por la enfermedad, pero la cepa Psph67 tuvo mayor virulencia (Figura 6A, B). Para el experimento de biocontrol con bacteriófagos se empleó solo la cepa con mayor virulencia, provocando los 


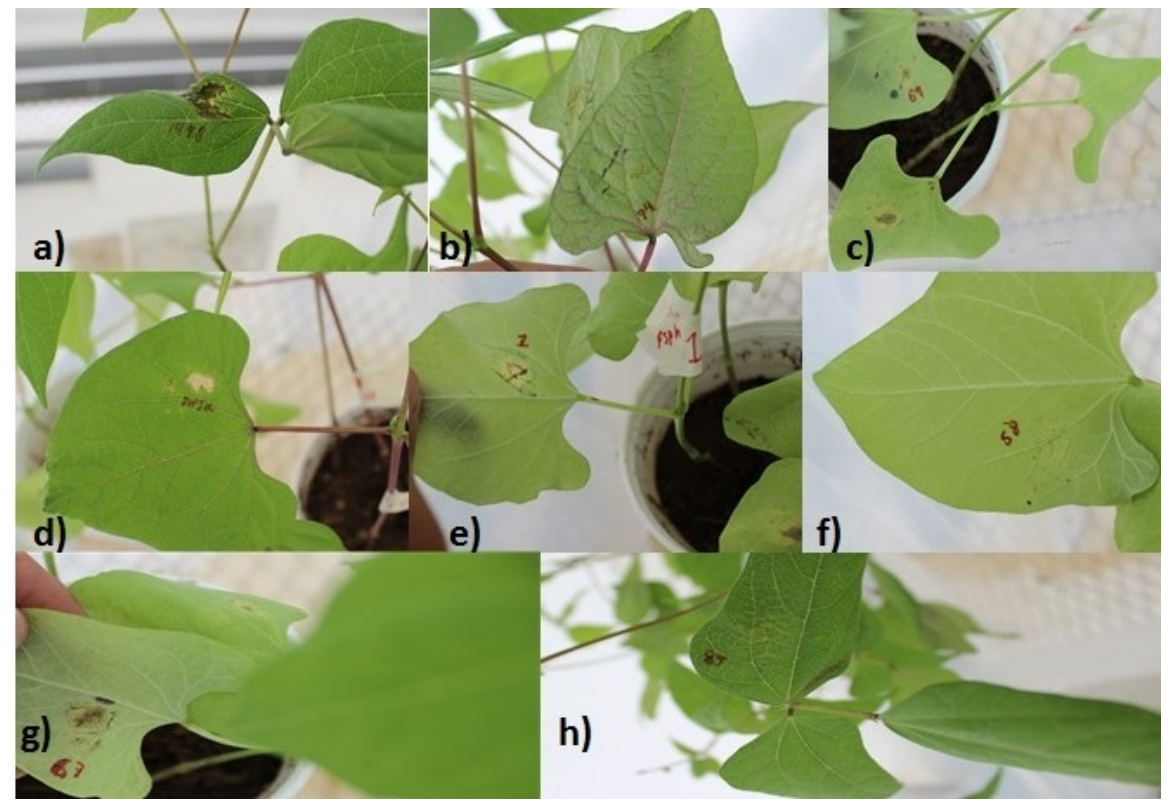

Figura 7. Síntomas del tizón de halo (manchas cloróticas o necróticas) en hojas de frijol de distintas variedades producidas por diferentes cepas bacterianas: a) Psph1448A; b) Psph74; c) Psph69; d) DH5 $\alpha$ de E. coli; e) Psph1; f) Psph58; g) Psph67; h) Psph82.

seis bacteriófagos lisis a nivel in vitro; además de la cepa con menor virulencia (Psph1) con uno de sus bacteriófagos líticos (F1.1).

\section{Evaluación de la patogenicidad de Psph en plantas de frijol}

La patogenicidad de las cepas de Psph se evaluó en plantas de frijol por observación de la presencia o no de halos cloróticos producidos por la bacteria fitopatógena. A partir de estas observaciones de la sintomatología en las plantas inoculadas con Psph se determinó que todas las cepas Psph tuvieron síntomas típicos de la enfermedad, principalmente en el control positivo $1448 \mathrm{~A}$, mientras que el control negativo la cepa $\mathrm{DH} 5 \alpha$ de $E$. coli no presentó síntomas de tizón de halo (Figura 7).

Evaluación de la efectividad de siete bacteriófagos para el biocontrol de Psph en ejotes de frijol

Se encontraron diferencias estadísticas entre tratamientos $(p \leq 0.05)$, presentando los controles sin bacteriófago (Psph1448A y Psph1) la mayor área de daño (Figura 8A, B). La inoculación con el bacteriófago F2 disminuyó de forma significativa $(\mathrm{p} \leq 0.05)$ el área de daño provocado por la cepa Psph1448A de Psph (Figura 8A). Los bacteriófagos F1, F3, F4 y F6 tuvieron un área de daño estadísticamente similar a la provocada cuando no hubo bacteriófago (tratamiento 1448A sin bacteriófago). Por otro lado, el tizón de halo en el tratamiento donde se aplicó el bacteriófago F1.1 de la cepa Psph1 fue estadísticamente similar al daño provocado por la cepa Psph1. El bacteriófago F2 mostró una reducción significativa del tizón de halo del $60 \%$ con respecto al tratamiento sin bacteriófago en ejotes de frijol de la variedad Flor de Mayo.

\section{DISCUSIÓN}

Las diferentes cepas de $P$. syringae pv. phaseolicola mostraron síntomas de tizón de halo en todas las pruebas de patogenicidad realizadas en ejote; la cepa $1448 \mathrm{~A}$ mostró mayor grado de virulencia, debido a que es modelo de estudio de esta enfermedad (Joardar et al. 2005, Mansfield et al. 2012). El grado de virulencia de esta cepa se reflejó en los resultados obtenidos al provocar mayor 
(A)

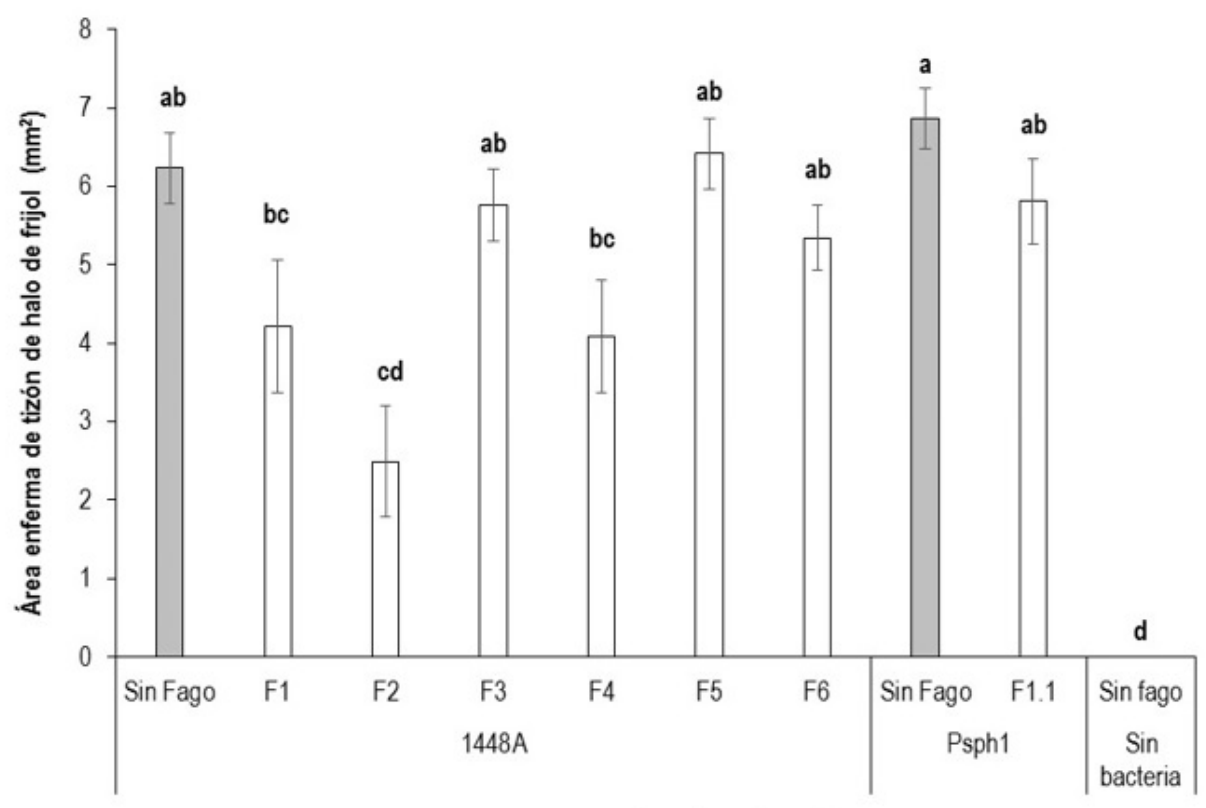

Cepa bacteriana fitopatógena

(B)
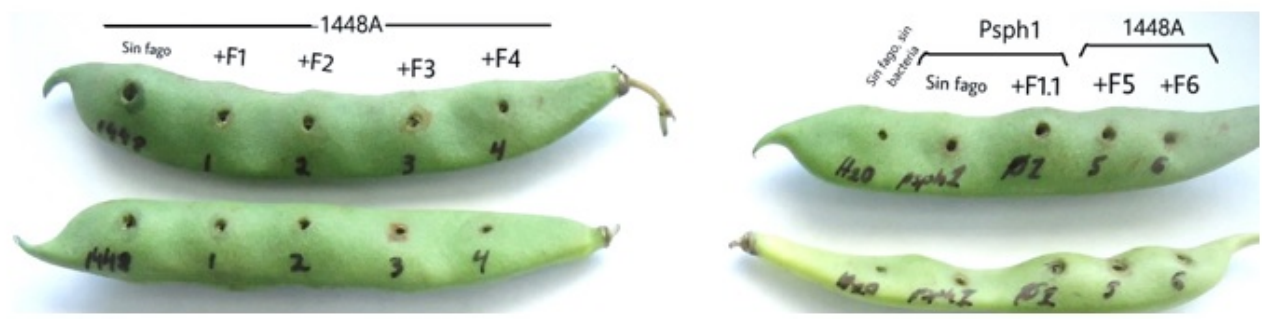

Figura 8. Control biológico del agente causal del tizón de halo Pseudomonas syringae pv. phaseolicola (Psph) por efecto de la inoculación de bacteriófagos (F1, F2, F3, F4, F5, F6 y F1.1) en ejotes de frijol de la variedad Flor de Mayo. (A) Letras diferentes indican diferencias estadísticas de acuerdo con Tukey $(p \leq 0.05)$. Las barras en cada rectángulo indican \pm el error estándar; las barras grises son tratamientos sin bacteriófagos. Sin fago y sin bacteria equivale a inocular $\mathrm{H}_{2} \mathrm{O}$. (B) Disminución del tizón de halo por efecto de la inoculación de bacteriófagos en las cepas 1448A o Psph1.

daño en los ejotes de las variedades de frijol empleadas; las cepas Psph1 y Psph67 también fueron virulentas, aunque estadísticamente menos virulentas que la 1448A. Debido a que todas las cepas fueron patogénicas en ejotes y en plantas de frijol, fue necesario aislar bacteriófagos con actividad lítica específica contra esas cepas de Psph. A pesar de que la actividad lítica de los bacteriófagos puede ser amplia en distintas cepas bacterianas de una misma especie, es común que presenten especificidad por alguna cepa o grupo de cepas particular, por lo que es un requisito importante emplear cepas nativas de
Psph para el aislamiento de bacteriófagos específicos de la zona donde se encuentra la problemática a resolver (Jones et al. 2007, Kolozsváriné et al. 2012). Con respecto a lo anterior, se aislaron bacteriófagos a partir de suelo o plantas de frijol donde se encontró el tizón de halo, esto con el fin de incrementar la posibilidad de encontrar bacteriófagos con actividad lítica; encontrándose siete bacteriófagos. De esta manera, este banco de bacteriófagos puede ser aplicado en forma combinada con otros microorganismos benéficos para lograr mejores resultados en el control de enfermedades bacterianas 


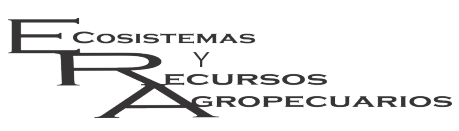

(Kolozsváriné et al. 2012).

Los resultados de las pruebas de actividad lítica de los bacteriófagos nativos contra la cepa Psph1448A muestran que el fago F2 disminuyó hasta un $60 \%$ el tizón de halo. Resultados similares fueron reportados por Adachi et al. (2012), quienes indican que con el bacteriófago BGPP-Ar disminuyó la pudrición en plantas de arroz causada por las bacterias Burkholderia glumae y Burkholderia plantarii. También se ha reportado que los bacteriófagos son capaces de disminuir el efecto de bacterias fitopatógenas a través de otros mecanismos distintos a la lisis, al respecto Ahmad et al. (2014) encontraron que el bacteriófago XacF1 inoculado con Xanthomonas axonopodis pv. citri provocó cambios fisiológicos en las células hospedantes, como bajos niveles de producción extracelular de polisacáridos, reducción de la motilidad, tasa lenta de crecimiento bacteriana y reducción de la virulencia.

Los resultados refuerzan el potencial uso de bacteriófagos en el control biológico de enfermedades causadas por bacterias fitopatógenas (Obradovic 2009). Pero es necesario investigar más sobre las relaciones complejas hospedantebacteriófago, debido a que bacteriófagos lisogénicos pueden convertir bacterias no patógenas en patógenas insertando genes que codifican para fitotoxinas (Goodridge 2004). Por lo que es recomendable el empleo de bacteriófagos estrictamente líticos, dado que es poco común que un bacteriófago presente ambos ciclos (Hernández y Castellano 2014). Otra complicación sobre el uso de bacteriófagos en el control biológico gira en torno a que las bacterias fitopatógenas tienen la capacidad de adquirir resistencia a la infección viral, de manera análoga a como lo hacen con los antibióticos (Gill y Abedon 2003), sin embargo, los bacteriófagos poseen la capacidad de mutar y por lo tanto volver a infectar al hospedante o a otras cepas fitopatógenas (Goodridge 2004). Se encontró una reducción del daño provocado por Psph en ejotes bajo condiciones controladas de luz y temperatura, sin embargo para que la aplicación de bacteriófagos sea efectiva bajo
Quiñones-Aguilar et al. Biocontrol de Pseudomonas syringae mediante bacteriófagos Ecosist. Recur. Agropec. 5(14):191-202,2018

condiciones de invernadero y campo es necesario el desarrollo de estrategias de protección de las partículas virales entre las cuales se encuentran: el empleo de bacterias susceptibles al bacteriófago que puedan ser inoculadas en la filósfera para incrementar el período de permanencia del virus en las hojas, la aplicación por la mañana o por la tarde-noche del producto a base de bacteriófagos, cuando la radiación ultravioleta disminuye y el desarrollo de formulaciones protectoras de los bacteriófagos (Jones et al. 2012). Al respecto Marroni y Germani (2014) desarrollaron una suspensión que contenía hojas de col con lesiones bacterianas, medio de cultivo líquido (GYCA), bacterias susceptibles y sacarosa, encontrando un decremento en el índice de severidad de Xanthomonas campestris pv. campestris en hojas de col (Brassica oleracea capitata). También se ha investigado la penetración y translocación de bacteriófagos en diferentes tejidos de planta y su capacidad para reducir la severidad de bacterias fitopatógenas, encontrando que los bacteriófagos $\phi \mathrm{Ea104}$ y $\mathrm{H} 5 \mathrm{~K}$ se translocaron en el tejido vegetal de plántulas de manzano, reduciendo el daño provocado por Erwinia amylovora (Kolozsváriné et al. 2015).

\section{CONCLUSIONES}

El aislamiento de bacteriófagos con actividad lítica contra cepas virulentas de Pseudomonas syringae pv. phaseolicola, agente causal del tizón de halo en frijol puede ser una alternativa prometedora para su aplicación dentro del control biológico de esta bacteria fitopatógena. Se encontró un bacteriófago (F2) con capacidad para disminuir el daño provocado por Psph en ejote hasta en un $60 \%$.

\section{AGRADECIMIENTOS}

Al Fondo Mixto del gobierno del estado de Zacatecas y el CONACYT, por el financiamiento del proyecto ZAC-2013-C01-201702. 


\section{LITERATURA CITADA}

Adachi N, Tsukamoto S, Inoue Y, Azegami K (2012) Control of bacterial seedling rot and seedling blight of rice by bacteriophage. Plant Disease 96: 1033-1036.

Ahmad AA, Askora A, Kawasaki T, Fujie M, Yamada T (2014) The filamentous phage XacF1 causes loss of virulence in Xanthomonas axonopodis pv. citri, the causative agent of citrus canker disease. Frontiers in Microbiology 5: 1-11.

Balogh B, Canteros BI, Stall RE, Jones JB (2008) Control of citrus canker and citrus bacterial spot with bacteriophages. Plant Disease 92: 1048-1052.

Balogh B, Jones JB, Iriarte FB, Momol MT (2010) Phage therapy for plant disease control. Current Pharmaceutical Biotechnology 11: 48-57.

d'Herelle MF (1917) Sur un microbe invisible antagoniste des bacilles dysentériques. Comptes Rendus de l'Académie des Sciences 165:373-375.

Frampton RA, Pitman AR, Fineran PC (2012) Advances in bacteriophage-mediated control of plant pathogens. International Journal of Microbiology 2012: 326452. Doi 10.1155/2012/326452.

Gill J, Abedon ST (2003) Bacteriophage ecology and plants. APS net http://www.apsnet.org/publications/ap snetfeatures/Documents/2003/BacteriophageEcology.pdf Fecha de consulta 1 de mayo de 2016.

Goodridge LD (2004) Bacteriophage biocontrol of plant pathogens: fact or fiction. Trends in Biotechnology 22: 384-385.

Hernández CRE, Castellanos GL (2014) Uso de los bacteriófagos en el sector agropecuario. Agroecosistemas 2: 361-371.

Iriarte FB, Balogh B, Momol MT, Smith LM, Wilson M, Jones JB (2007) Factors affecting survival of bacteriophage on tomato leaf surfaces. Applied and Environmental Microbiology 73: 1704-1711.

Iriarte FB, Obradovic A, Wernsing MH, Jackson LE, Balogh B, Hong JA, et al. (2012) Soil-based systemic delivery and phyllosphere in vivo propagation of bacteriophages two possible strategies for improving bacteriophage persistence for plant disease control. Bacteriophage 2: 215-224.

Jensen MA, Webster JA, Straus N (1993) Rapid identification of bacteria on the basis of polymerase chain reaction-amplified ribosomal DNA spacer polymorphisms. Applied and Environmental Microbiology 59: 945-952.

Joardar V, Lindeberg M, Jackson RW, Selengut J, Dodson R, Brinkac LM, et al. (2005) Whole-genome sequence analysis of Pseudomonas syringae pv. phaseolicola 1448A reveals divergence among pathovars in genes involved in virulence and transposition. Journal of Bacteriology 187: 6488-6498.

Jones JB, Jackson LE, Balogh B, Obradovic A, Iriarte FB, Momol MT (2007) Bacteriophages for plant disease control. Annual Review of Phytopathology 45: 245-262.

Jones JB, Vallad GE, Iriarte FB, Obradovic A, Wernsing MH, Jackson LE, et al. (2012) Considerations for using bacteriophages for plant disease control. Bacteriophage 2: 208-214.

Kolozsváriné NJ, Király L, Schwarczinger I (2012) Phage therapy for plant disease control with a focus on fire blight. Central European Journal of Biology 7: 1-12.

Kolozsváriné NJ, Schwarczinger I, Künstler A, Pogány M, Király L (2015) Penetration and translocation of Erwinia amylovora-specific bacteriophages in apple-a possibility of enhanced control of fire blight. European Journal of Plant Pathology 142: 815-827. 
Lara-Flores ML (2015) El cultivo del frijol en México. Revista Digital Universitaria 16: 1-11.

Lépiz-Ildefonso R, Sánchez PS, López AE, López AJJ, Chavarín EIE, Meza VKE (2015) El cultivo del frijol en Jalisco: tecnología para altos rendimientos. Ed. Universidad de Guadalajara. México. 54p

Marroni IV, Germani JC (2014) New technique to create a suspension containing bacteriophages and how it can be used to control cabbage leaf spot caused by Xanthomonas campestris pv. campestris. Agricultural Sciences 5: 286-297.

Mansfield J, Genin S, Magori S, Citovsky V, Sriariyanum M, Ronald P, et al. (2012) Top 10 plant pathogenic bacteria in molecular plant pathology. Molecular Plant Pathology 13: 614-629.

Obradovic A (2009) Bakteriofagi kao baktericidi u zaštiti bilja. Pesticidi i fitomedicina 24: 9-17.

Prudencio-Sains JM, Navarrete-Maya R, Navarrete-Maya J, Acosta-Gallegos JA (2008) Dinámica de los tizones común y de halo del frijol en el valle de México. Agricultura Técnica en México 34: 201-212.

Reyes-Tena A, Rincón-Enríquez G, Evangelista-Martínez Z, Quiñones-Aguilar E, López-Pérez L (2015) Lucha entre microbios: una herramienta para el control biológico de enfermedades de plantas. Revista Digital Universitaria 16: 1-15.

Schwartz HF, Pasto-Corrales A (1989) Halo bligth. In: bean production problems in the tropics. CIAT (ed), Cali Colombia. pp: 285-301. 